\title{
The relation of minority group's sport attainment to counter racism: African-American in the movie 42
}

\author{
Triastama Wiraatmaja* \\ English Language Education Department, \\ Faculty of Teacher Training and Education \\ Universitas Muhammadiyah Malang, Indonesia \\ ${ }^{*}$ Corresponding Author \\ Email: triastama@umm.ac.id
}

\begin{abstract}
This study was conducted to determine the efforts made by minority groups who are being oppressed by racism based on context-relationship of African Americans at the movie 42 (2013). Findings of this article based on qualitative studies with auteur theory, and mise-en scene, undertaken in movie 42 (2013) regarding racism towards minority groups, African-American, and by implementing thick description the researcher highlighted minority group's achievement's at the movie 42 in the field of Sports and the relation to life-betterment. The result revealed that racism towards minority group had emerged because of the so-called white's supremacy concept. This study found that African American as minority group were able to alter their life despite of racism through equal sport's opportunity. Besides, this study has highlighted one pivotal area in which any minority group should concern to enhance their life; sports. Moreover, even though this study focusing more on the relation of the effort's made by minority group at America, this study illustrates the importance of having initiatives in providing better opportunity related to sports to ensure a better life opportunity among minority groups all over the globe.
\end{abstract}

Keywords: racism; auteur theory; mise-en scene; thick description; sports; white supremacy

Received:

Revised:

Accepted:

Published:

26 November 20186 February 2019

28 February 2019

28 February 2019

\section{INTRODUCTION}

O'er the land of the free and home of the brave!

The aforementioned statement was part of Star-Spangled Banner, the national anthem of the United States of America. In which, it would be the centre of this research that emphasizing America as a land of freedom that suffered from inequality and injustice towards people of coloured or minority group, however some of the bravest individuals stood up against the racism 
towards them. The researcher emphasized the racism towards one of the famous minority groups that already experienced racism first-hand, the African-American. The researcher then highlighted racism towards African American at the field of sports. In which, despite of the last part of America national anthem that highlighted America as a land of freedom, racism haunted the minority group or the coloured people, yet not all African American were kept quiet about the white's oppression and one individual were bravely stepped on baseball court in search of life betterment, one of which was Jack Robinson, the first coloured professional baseball player at America.

In fact, there were not any records regarding registered coloured athletes at the Major League Baseball before the year of 1947. However, Jack or Jackie Robinson were not giving up, and accepting his status as second-tier citizens, or minority groups. Jackie Robinson were brave enough to step in the same field as the white's people and led to the historical landmark at the field of sports; Jackie Robinson recorded as the first coloured or the first African American athletes who were able to break the colour or racial barriers by joining The Brooklyn Dodgers at April 15th 1947. Jackie's efforts eventually being honoured by having his career, as The Brooklyn Dodgers players, were finally filmed by Hollywood at 2013 by the title 42 . This biopic film regarded as the chronicles of Jackie Robinson's early professional career from 1946 until the Dodger able to clinch the pennant at 1947, which becoming the main highlight of his remaining careers.

Many cinemagoers and sport pundits acknowledged this film as the most realistic and authentic baseball film which was able to depict every inch of baseball history during Jackie's early years at the Brooklyn Dodgers. However, Jackie Robinson's hardship in that cinema not only depicted about his struggles during his career as athletes, but also when he had to fight against racism towards coloured people, or minority group. Jackie also had to prove every baseball fans at America that African American deserved a chance to compete at professional leagues. According to the news under the title 42 Depicts Jackie Robinson's Struggles as MLB Marks Baseball Integration from The Guardian at April 15th 2013, the biopic film entitled 42 was trying to commemorate the 66 years since Jackie Robinson broke baseball's colour line. In other words, The Guardian were trying to keep the memory of Jackie's hardship never go to waste and trying to refresh every African American's regarding Jackie's story.

Henceforth, the researcher inquired the research questions regarding this research as follow; how the racism is being depicted towards Jackie Robinson as the only minority or coloured baseball player in the movie 42 . Therefore, the researcher deemed that every minority groups all over the globe should reflect upon African American heroic efforts to counter racism, prejudice and discrimination towards them. The efforts done by African American such as striving to excel at sports could be the key in altering negative stereotyped towards them. Furthermore, this research hopefully would be able to assist or elaborate the minority group's efforts in the search of life betterment despite of the racism addressed towards them. The efforts shown by African American in fighting racism, especially in the field of sports, hopefully might initiates and motivate the minority groups in search of life betterment. 


\section{Racism and racist ideology towards minority groups}

To constitute comprehension regarding the concept of race with racism, the researcher regarded that the majority or superior group will most likely try to assert or maintain their dominance over less superior group by utilizing the idea of racism as a method to assert or to maintain their dominance or superiority over the inferior or minority group. This statement backed up by Ferris and Stein (2010:249) as follow, an ideology or set of beliefs about the superiority of one racial or ethnic group over another provides this support; it is used to justify social arrangements between the dominant and minority groups. Thereby, the researcher regarded racism as an ideology that justifying a certain group possesses superiority towards another group that strengthens the gap between majority and the minority. Then, the racist ideology among majority were falsely utilized to gain advantage over minority group, or to maintain the dominance or social arrangements among majority and minority.

Next, the racist ideology being specified into the so-called White Supremacy ideology, an ideology that tried to devise an environment that emphasise on social arrangements that maintain white's superiority and African American inferiority. Racist ideology as the fundamental concept of white supremacy explained by Ferrante (2008: 252) as follow,

People who embrace racist ideology believe that something in the biological makeup of an ethnic or racial group explains and justifies its subordinate or superior status. Racist ideologies are structured around three notions:

1. People can be classified according to physical characteristics. 2. A close correspondence exists between physical traits and characteristics such as language, dress, personality, intelligence, and athletic ability.

3. Physical attributes such as skin color and hair texture are so significant that they explain and determine behavior and inequalities.

Then, the researcher deemed ideology as portion of culture that able to be recognized via signs and symbols. In other words, the symbols in society also could be understood as the product of human interactions, communication, or reports regarding social issues, one of which is by studying related pictures or videos. As explained by Geertz (1973), culture is a system of inherited conceptions expressed in symbolic forms by means of which men communicate, perpetuate, and develop their knowledge about and attitudes towards life.

The researcher concluded that the notion of African American's inferiority existed because of the stereotyped that being manifested by white's people at America as majority. Stereotyped could be explained by Hess, Markson, and Stein (1993:256) as follow, stereotyped itself might be defined as, an image in which a single set of characteristics, favorable or unfavorable, is attributed to entire group. Hence, the stereotyped that have been addressed towards African American, which is regarded as negative attributes, could be infer as follow; lazy, uneducated, illiterate, and inferior. The aforementioned stereotyped were being addressed towards group of people from African's descent since the slavery began in America at $17^{\text {th }}$ century. Tindall (2013:118) also explain that idea as follows;

The English in the seventeenth century associated the color black with darkness and evil; they stamped the different 


\begin{abstract}
appearance, behavior, and customs of Africans as "savagery." Most of the self-serving qualities that colonial Virginians imputed to blacks to justify slavery were the same qualities that the English assigned to their own poor to explain their lowly status: their alleged bent for laziness, treachery, and stupidity, among other shortcomings.
\end{abstract}

Therefore, the researcher employed the concepts of racism, ideology, stereotyped, prejudice and discrimination to understand and analyze racism between the race-relationship of majority group, whites American, and minority group, African American, in the movie 42.

\title{
Auteur theory and mise-en scene
}

The researcher utilised Auteur Theory to show the concept of racism towards people of coloured as minority, and the people of coloured efforts in countering racism towards them according in the movie 42. Auteur Theory according to Shafrir (2006) could be inferred as, the auteur theory is a way of reading and appraising films through the imprint of an auteur (author), usually meant to be the director. Basing on that, the researcher keen to reveal the ideas of racism that have been delivered via the film 42 by the film director; the racism addressed towards Jackie as African American Athletes, and from the point of view of Jackie's efforts as an athlete to counter racism towards people of coloured, African American, who competed at professional baseball.

In other words, the researcher argues that the idea of implementing the portrayal of racism and resistance against racism at 42, were being regarded as having the same concept of the implementation of Auteur Theory in the cinema. As justified by Shafrir (2006) as follow, the key thing is that a recognisable imprint is left on a body of films, and this may involve varying levels of creative input. Furthermore, to discover the values addressed at the film, the researcher utilized a method known as mise-en scene (read meez-ahnsen) as an effort to constitute an understanding of how to understand the values of the film.

Mise-en-scene according to Bordwell and Thompson (2008) inferred as, putting into the scene, and it was first applied of directing plays. According to the previous statement, the researcher argued that the cinema director is trying to implant their values and ideas within the cinema by perpetually repeating the scenes which have the same values and ideas. Moreover, Bordwell and Thompson (2008:115) explain about the methods of analyzing cinema using mise-en scene, As you would expect, mise-en scene includes those aspects of film that overlap with the art of the theatre; setting, lighting, costumes, and the behaviour of the figures. In controlling the mise-en scene, the director stages the event for the camera. However, the researcher only focused on the behaviour of the figures out of other aspects at mise-en scene when conducting this research. Precisely, because of the researcher observed that the behaviour of the figures including the dialogues or the script and the staging of the actor and actresses are the most pivotal aspect found at the film 42. The researcher regarded that behaviour of the figure include the gestures of the actor within the movie, because gestures of the actor and actresses in the movie being directed according to the dialogues and the script. As behaviour of the figures according to Lathrop and Sutton (2014: 3) defined as follow; 
Figure expression refers to the facial expressions and the posture of an actor, whereas figure movement refers to all other actions of the actor, including gestures. Two of the most important aspects of film study are appropriateness of the expression of the actors and the control the director exhibits over the actor's movements.

Therefore, the researcher would be able to differentiate, and classifying the values that carried out by the cinema director. As a result, the researcher was able to determine the selected elements of mise-en scene, which is the behaviour of the figures in order to expose the issues or values regarding racism towards minority group, specifically an African American known as Jackie Robinson at the film 42. Furthermore, by using mise-en scene the researcher was able to interpret racism towards minority groups and Jackie's effort to counter the effect of racism towards minority group, people of colour, through achievement at sports; baseball.

\section{Thick description}

Henceforth, the researcher regarded this research as visual ethnographic study, because it deals with film or moving picture to highlight the concept of racism towards minority group, African American. The study regarding visual ethnography according to Pink (2006) as cited at Kharel (2015) could be defined as follow; images are inextricably tied up with our daily life, personal identities, narratives, lifestyles, cultures, and societies, as well as with definitions of history, space, and truth. Ethnographic research is likewise intertwined with visual images and socio-cultural representations. Thus, as conducting visual ethnographic research, the researcher able to discover and classify the socio-cultural values in the movie 42, especially regarding racism towards African American as minority group.

Therefore, as this research regarded as the visual ethnographic study, the researcher tried to interpret and analyze the data taken from Mise-en scene by employing Thick Description. Via Thick Description, the researcher attempted to investigate the symbolical system, and in-depth study regarding the cultural values, and produce facts, deep explanation, comments, and interpretations regarding the addressed value regarding racism in the movie 42. The researcher deemed that visual ethnographic study also symbolize the essence of an ethnographic study because both of them attempted to discover the notion within society by clarifying and providing proves. As Geertz (1973: 16) suggested as follow:

The claim to attention of an ethnographic account does not rest on its author's ability to capture primitive facts in faraway places and carry them home like a mask or carving, but on the degree to which he is able to clarify what goes on in such places, to reduce the puzzlement-what manner of men are these.

Following the previous explanation, the researcher tried to emulate the similar approach in order to constitute interpretations of cultures and racial issued according to the context of the movie 42 by interpreting and analysing cultural symbols and values depicted by the actors and actresses at the film, so the researcher able to analyse the set of beliefs, settings of behaviours, technology, clothing style, political and economic system, even sports portrayed by the actors and actresses in the movie 42 as they are performing 
cultural values regarding racism in the movie 42. The aforementioned arguments by the researcher also supported by Crawford (1992) cited at Kharel (2015);

...in visual ethnographic research environment, Geertz's idea of "thick description" can be achieved by images, gestures, or sequences that convey meaning. Thickness is created by the ability of the visual description to transmit what is really being 'said'. In ethnographic filmmaking, "thick descriptions" result from what has been recorded and edited.

As explained by Geertz (1973:12), culture is public because meaning is. The researcher argued that culture is the representation or the imagery of the society that includes human interaction as social group, in which consist of set of beliefs, and behaviours. Therefore, by utilizing Thick Descriptions and basing on the context of the film 42, the researcher tried to convey the issue regarding racism at sports performed by whites as majority groups towards African American as minority groups. Specifically the researcher tried to highlight the issue of racism towards the first coloured athletes at American's sports who break the colour barrier at Major League Baseball; Jackie Robinson.

\section{METHOD}

The researcher used qualitative studies with auteur theory, and mise-en scene, undertaken in movie 42 (2013) regarding racism towards minority groups, African-American, and by implementing thick description the researcher highlighted minority group's achievement's at the movie 42 in the field of Sports and the relation to life-betterment.

\section{RESULTS AND DISCUSSION \\ Results}

The findings are presented at one sub-section; particularly the scene regarding behaviour of the figures; racism towards Jackie Robinson as the only minority or coloured baseball player in the movie 42 .

\section{Racism towards Jackie Robinson, the only minority or coloured baseball player in the movie 42}

At this section the researcher chose a selected scene from the 42 that last from the 01:13:00-01:25:00, a scene that shown Jackie Robinson, as the Brooklyn Dodger player, who was up to bat against Philadelphia Phillies. The researcher argued that this scene shown the portrayal of racism employed by Ben Chapman, a white man, towards Jackie Robinson as the first coloured athletes at Major League Baseball, and as the member of minority group, African American. The researcher also perceived this scene as Jackie's positive remarks regarding Ben Chapman racial abuse towards him as a conduct of sportsmanship. 
Wiraatmaja, EduLite: Journal of English Education, Literature, and Culture Vol.4, No.1, February 2019 , 76-86 DOI: $h t t p: / / d x . d o i . o r g / 10.30659 /$ e.4.1.76-86

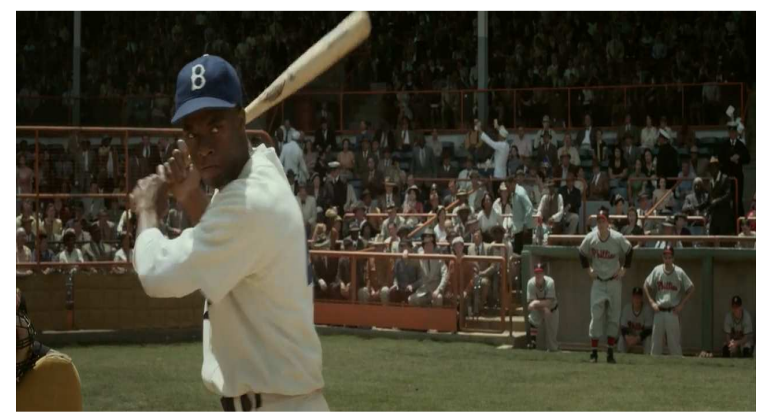

Figure 1: Representation of Jack Robinson who was up to bat when receiving White's racial abuse by Ben Chapman (Philadelphia Phillies' coach) towards Jack Robinson. Source: 42 (2013)

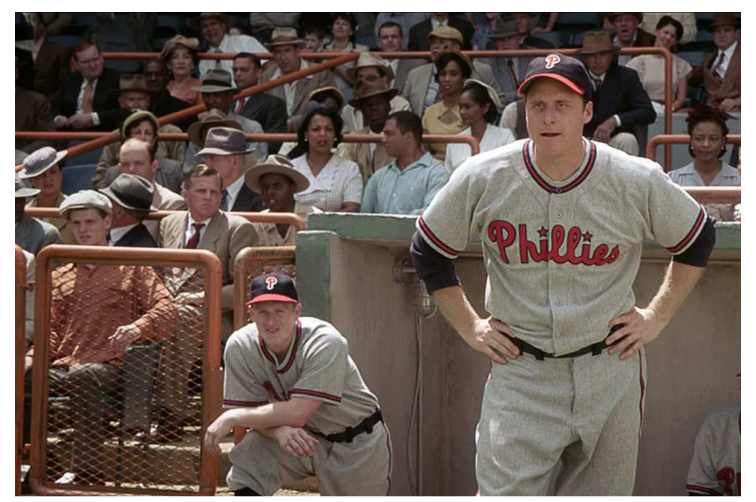

Figure 2: Representation of White's racial abuse by Ben Chapman (Philadelphia Phillies' coach) towards Jack Robinson when he was up to bat. Sources: 42 (2013)

The scenes above were depicted to happen at the same time. At the both of the chosen scenes above the researcher perceived one of the elements at mise-en scene that represented the notion of white's racism towards African American; staging or behaviour of the figures. In which, this aspect represented by the gestures, dialogues or the scripts of the portrayed scene regarding Ben Chapman's racist behaviours towards Jackie Robinson. Ben Chapman was shown insulted and harassed Jackie Robinson by spouting, Why don't you go back to the cotton fields where you belong!, Or did you swing your way out of the jungle?! Bring me a banana!. According to the previous dialogues by Ben Chapman's insult, harassment and verbal discrimination towards Jackie Robinson, the researcher then able to infer that Ben Chapman was referring to the history African American as descendent of slaves, and the colour of Jackie's biological make-up that identical to ape, which is black.

In other words, the researcher argued that by referring to the history of slavery and the skin complexion of African American, Ben Chapman had depicted the white's stereotyped towards African American; bone-idle, uneducated, illiterate, and barbaric. Therefore, Ben Chapman's had shown stereotyped attributed towards African American that categorized African American as subordinate, and white's as superior. Afterwards, the stereotyped and subordinate status of African American had contribute to the emergence 
of white supremacy among white's as majority group at America, hence the notion of white's superiority and African American inferiority made the white regard themselves possess control, and have rights to dominate the African American. However, the researcher here also focuses on the positive remarks by Jackie Robinson although he was racially abuse by Ben Chapman, as portrayed at the selected scene above. In which, although Jackie was receiving verbal abuse, he was able to keep silent and focused on winning the match by showing dedication, work-ethics, professionalism, and natural talents. In the end, by fully utilized his talent at that scene, Jackie was able to pull through the challenge, either racial or professional challenged as baseball player, and led his team won against Ben Chapman's the Philadelphia Phillies by narrow margin, 1-0.

\section{Discussion}

This research regarding racial discrimination towards Jackie Robinson as the only minority or coloured, African American, baseball player in the movie 42 highlighted that racism towards people of coloured, notably the African American, emerged because of the slave-stereotyping and the imagery of their biological make-up. As explained by Tindall (2013:118) as follow;

The English in the seventeenth century associated the color black with darkness and evil; they stamped the different appearance, behavior, and customs of Africans as "savagery." Most of the self-serving qualities that colonial Virginians imputed to blacks to justify slavery were the same qualities that the English assigned to their own poor to explain their lowly status: their alleged bent for laziness, treachery, and stupidity, among other shortcomings.

Next, the stereotyped above had become the foundation of racism or racist ideology towards African American as depicted in the movie 42. In which, racism or racist ideology performed by whites towards African American known as the white supremacy, an ideology that embedded at white's people or majority group at United States of America. Hence, by employing white supremacy theory, the white's was trying to assert or maintain their dominance over African American. As Hooks (1992:340) clearly stated below;

In white supremacy society, white people can "safely" imagine that they are invisible to black people since the power they have historically asserted, and even now collectively assert over black people accorded them the right to control the black gaze.

As depicted in the movie 42, the researcher also inferred that racism towards African American, as minority group, still exists because of the white supremacy concept at baseball regarded as part of white's social convention. This statement supported by Souffrant (2013: 156) as stated below, Where a course of action is morally required to bring about or restore a public state of affairs and, consistent with the individualist interpretation of morality, no one is immediately responsible for performing it, Goodin argues that we are all collectively responsible for doing what needs to be done. Indeed, the principle of protecting the vulnerable found at the core of his ethics of responsibility rests on the realization that whether one is made vulnerable by nature or by certain social conventions, 
the members of a moral community have, whether singly or collectively, a responsibility vis-a-vis the vulnerable to alleviate the latter's vulnerability.

Therefore, as methods to assert or maintain their dominance and as the implementation of their white supremacy ideology, the majority or whites as depicted in the movie 42 had to utilise the so-called discrimination. In which, the researcher regarded that whites', as depicted in the movie 42, had performed the so-called institutionalized discrimination. As institutionalized discrimination explained by Ferris and Stein (2010: 249), institutionalised discrimination, in contrast, usually more systematic and widespread, occurs when institutions (such as government, schools, or banks) practice discriminatory policies that affect whole groups of individuals. Basing on that, the researcher also able to infer that white's regarded the Major League Baseball of America as their privilege, but since Jackie joined the Brooklyn Dodgers at 1947. The whites had a feeling that their privilege was being confronted, so the whites had to utilise racism followed by institutionalised discrimination as a method to maintain their dominance.

More importantly, the researcher also highlighted Jackie's remarks regarding the racism that had been addressed towards him. In which, despite the racism, and institutionalised discrimination towards African American as minority group at baseball, Jackie Robinson was able to keep on playing baseball at professional level. Plus the researcher perceived he was able to counter racism by showing the conduct of sportsmanship; professionalism, dedication, and work ethics.

However, the researcher also perceived the downfall of sports among African American as minority groups at America; the girls of colours are at disadvantage when it comes to play sports at High School. The researcher also regarded that, although minority group, African American, were given equality and equity a sports, it does not guarantee that sports would be able to alter their life to the better. Therefore, sports equality towards minority groups is highly advisable to reach mutual understanding and to nurture equal understanding about sportsmanship to all parties.

In addition, the researcher also argued that the minorities perceive sports as social ladder to gain better life, or to improve their social class, especially the African American as minorities in America that struggled against racism while trying to pursue life betterment; social and economic status. As Jarvie and Reid (1997:218) pointed out that Sport has been viewed as a vehicle for valorizing black power, sporting skills as a means of marking racial self expression and sporting as a means of pursuing social and economic mobility. Therefore, the African American, as depicted by Jackie Robinson, identified sports as one of the means to reach life-betterment; because they believed that by reaching the status of sporting heroes of particular sport they would be seen as famous and wealthy individuals.

By having personal achievement at sports, the minority groups who previously belong to lower social class might climb up to the better position, the social class per se does not having any relation to race, ethnicity, gender, or age. As Ferris and Stein (2010:213) elaborated about social class, Social class, a system of stratification practiced primarily in capitalist society, ranks group of people according to their wealth, property, power, and prestige. In other words, the social class in America, being determined by how much 
money, power, and esteemed that were being possessed by someone, regardless the color of their skin, or the variety of their biological make-up. As a result, anyone could climb up to the status of celebrity or tycoon if they possess wealth, power, and prestige who distinguish them from others, including their fellow minority groups.

\section{CONCLUSION}

Based on the previous section, the researcher able to draw conclusions that racism towards Jackie Robinson as depicted in the movie 42 was due to the white supremacy ideology, in which the white utilized white supremacy ideology to assert and maintain their dominance over the minority group, especially the African American. The white supremacy ideology, among whites, emerged due the slave-stereotyping and the biological make-up of African American. Plus, the whites, as depicted in the movie 42, implemented institutionalized discrimination at professional baseball leagues at America to maintain their privilege as majority at Major League Baseball at America. However, the researcher also conclude that in order to constitute an understanding of how to counter racism, the African American as minority group has to possess Jackie's attributes as professional baseball player; conduct of sportsmanship under the threat of racism such as, professionalism, dedication, and work-ethics.

Henceforth, the researcher sees that sporting activities have changed the perspectives of sports among minorities, in which for minorities the sporting activities and sports attainment, being regarded as shortcut to climb up the social class or social ladder within particular society, notably if eventually they were able to gain fame, wealth and prestige. The researcher also discovered that the majority also have to possess initiative and accommodating the needs of the minority, notably to have equity and equality in every aspect, one of which is at sports.

As depicted in the movie 42 when the owner of the Brooklyn Dodgers, branch Rickey signed Jackie Robinson as the first coloured, or African American, baseball player. However, the researcher also exposed that sports among minority would not be able to fully facilitate and accommodate the needs of every minority groups, especially the girls of colour that at double disadvantage at playing sports at high school. Therefore, the researcher also suggested every minority groups to not only rely on the physical attributes, but also to excel at academics aspects.

\section{REFERENCES}

Bordwell, David. Thompson, Kristin. (2008) Film Art: An Introduction. New York: McGraw-Hill. pp. 112-161. Web <http://pages.ucsd.edu/ bgoldfarb/cogn21w10/reading/bordwell_ch4. pdf $>$ as of September 2015.

Ferrante, Joan. (2008). Sociology: A Global Perspective, Seventh Edition. Belmont: Thomson Wardsworth, a part of Thomson Corporation. 
Wiraatmaja, EduLite: Journal of English Education, Literature, and Culture Vol.4, No.1, February 2019 ,

Ferris, Kerry. Stein, Jill. (2010). The Real World $2^{\text {nd }}$ Edition, an introduction to Sociology. New York: W.W. Norton \& Company.

Geertz, Clifford. (1973). The Interpretation of Culture. USA: Basic Book Inc.

Harris, Leslie M. "African Americans." Microsoft ${ }^{\circledR}$ Encarta ${ }^{\circledR} 2009$ [DVD]. Redmond, WA: Microsoft Corporation, 2008.Accessed on September $18^{\text {th, }} 2018$.

Hess, Beth B. Markson, Elizabeth W. Stein, Peter J.(1993).Sociology Fourty Edition. New York : Macmillan Publishing Company.

Hooks, Bell. (1992). Representing whiteness in the black imagination. Cultural Studies. Grossberg, Lawrence Cary Nelson, Paula A. Trechler. London: Routledge. pp. 338-346. Web < http://1s-tlss.ucl.ac.uk/coursematerials/ELCS6088_74356.pdf> as of August 2018.

Jarvie, G. Reid, I. (1997). Race relations, sociology of sport and the new politics of race and racism. Journal Leisure Studies. Vol 16, 211-219. doi: https//doi.org/10.1080/026143697375296

Kharel, Dipesh. (2015) Visual Ethnography, Thick Description, and Cultural Representation. Journal of Sociology \& Anthropology. Vol. 9 ,pp. 147160. doi: http://dx.doi.org/10.3126/dsaj.v9i0.14026

Lathrop, Gail. Sutton, David O. (2014). Elements of Mise-en Scene. pp. 17. $<$ http://www.proseproductionsink.com/1102_Licata_Elements_of_Miseen-scene_modified.pdf $>$ as of August 2018

Shafrir, Doree._. Auteur Theory. _. pp. 1-4. Web $<$ https://id.scribd.com/document/53977760/Auteur-Theory> as of September 2015.

Souffrant, Eddy M. (2013). Identity, Political, Freedom, and Collective Responsibility. The Pillars and Foundations of Global Ethics. New York: Palgrave Macmillan.

Tindall, George Brown. Shi, David Emory. (2013). America: A Narrative History Vol 1. New York: WW Norton and Company.

The National Women's Law Center and The Poverty \& Race Research Action Council. (2015). Finishing Last, Girls of Color and School Sports Opportunities. National Women's Law Center. Web https://prrac.org/pdf/GirlsFinishingLast_Report.pdf as of August 2018. 